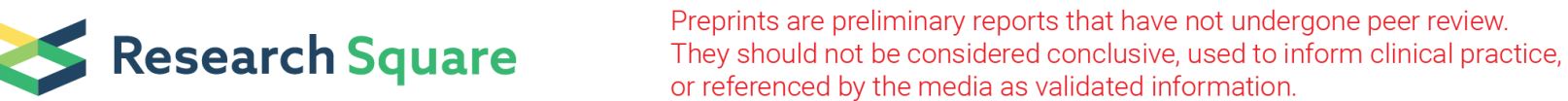

\section{Elevated Circulating Levels of N-Acetyl-Seryl- Aspartyl-Lysyl-Proline ( AcSDKP) Involved in Pancreatic Cancer Development}

Hendra Susanto ( $\square$ hendrabio@um.ac.id)

Universitas Negeri Malang https://orcid.org/0000-0002-3935-4848

Jerry Dwi Trijoyo Purnomo

Institut Teknologi Sepuluh Nopember

Chang-Chiang Chen

National Taiwan University Hospital Hsin-Chu Branch

Chih-Hong Wang

National Chiao Tung University College of Biological Science and Technology

Research article

Keywords: AcSDKP, prognostic factor, betatrophin, lipid metabolism, pancreatic cancer

Posted Date: May 7th, 2020

DOI: https://doi.org/10.21203/rs.3.rs-23986/v1

License: @ (i) This work is licensed under a Creative Commons Attribution 4.0 International License.

Read Full License 


\section{Abstract}

Background: Pancreatic cancer is the fourth leading cause of patient mortality with poor early prognosis. Lack of symptoms as early detection of this cancer has become the major problem for its clinical investigation. Thymosin $\beta-4$ (Tß4) has been associated with angiogenesis and metastasis in pancreatic cancer. Recently, N-Acetyl-Seryl-Aspartyl-Lysyl-Proline (AcSDKP), a

cleavage and active form of $T \beta 4$, is suggested related to systemic alteration to patients and involve in the Pancreatic Ductal Adenocarcinoma (PDAC) progression. However, the way this systemic change affected PDAC development is still not fully elucidated. This case-control study was conducted to evaluate the level of AcSDKP in health and pancreatic cancer patients

during the progression of pancreatic cancer development.

Methods: We analyzed 105 patients, including 15 healthy subjects and 90 pancreatic cancer subjects. The levels of AcSDKP were analyzed by Enzyme-Linked Immunosorbent Assay (ELISA) kit. Proliferation rate analysis was conducted using MTS assay in AsPC, HPAC, and PANC-1 cell line pre-treated by prolyl oligopeptidase (POP) inhibitor and AcSDKP polypeptide.

Results: Compared to healthy patients $(0.73 \pm 0.13)$, the levels of AcSDKP significantly increased in pancreatic cancer subjects (1.34 \pm 0.14$)$. AcSDKP induced pancreatic cell proliferation while inversely inhibited with POP inhibitor by in vitro analysis. Moreover, levels of AcSDKP were strongly positively correlated with pancreatic cancer status $(r=0.278, p=0.026)$, betatrophin $(r=0.270, p=0.025), \operatorname{ALP}(r=$ $0.267, p=0.034)$, ALT $(r=0.336, p=0.007)$, and AST $(r=0.255, p=0.042)$, while inversely correlated with cholesterol levels $(r=-0.250, p=0.046)$. Furthermore, in univariate and multivariate binary logistic regression analysis, the levels of AcSDKP showed a strong association with pancreatic cancer $[(p=$ $0.031, \mathrm{OR} \pm 95 \% \mathrm{Cl}=3.342(1.117-10.002)]$ and $[(p=0.024, \mathrm{OR} \pm 95 \% \mathrm{Cl}=4.324(1.030-18.148)]$. Quintile analysis showed that the level of AcSDKP has a strong association with betatrophin $[(p=0.033$, $\mathrm{OR} \pm 95 \% \mathrm{Cl}=5.623(1.142-24.266)]$.

Conclusions: AcSDKP can contribute to the progression of pancreatic cancer incidence and may indirectly be associated with liver lipid metabolism hormone as well as tumor cell proliferation. AcSDKP might be a potential additional predictor for pancreatic cancer.

\section{Background}

Pancreatic cancer-associated with long-standing diabetes as a risk factor for its development is the most common cause of mortality [1, 2]. Pancreatic ductal adenocarcinoma (PDAC) is a type of pancreatic cancer with an aggressive invasive phenotype, resistant to medical treatment, and the fourth leading cause of cancer deaths [3]. The higher incidence of mortality associated with pancreatic cancer is due to lack, as well as late symptoms and diagnosis; as a consequence, the probability of patient death caused by this disease significantly and steadily increases [2, 4]. A wide variety of serologic markers have 
been associated with pancreatic cancer. Therefore, surgical resection is only the standard curative therapy in pancreatic cancer due to a lack of prognosis marker in the early stages of this disease development. The future target is to improve the survival rate of pancreatic cancer patients. Therefore, identification of individuals at high risk for pancreatic cancer and early diagnosis could have a marked impact on reducing morbidity and mortality.

Previous studies have shown a causal relationship between Thymosin beta-4 (TR4), and the cleavage of $\mathrm{N}$-terminus of this peptide (AcSDKP) associated with tissue malignancy. The associations between Thymosin beta-4 (Tß4) and AcSDKP in some cancer pathogenesis have been well-established. Thymosin beta-4 (TR4) is overexpressed in several cancers, including colon cancer, bone cancer/osteosarcoma, renal cancer through inducing cell proliferation, migration via Integrin-linked kinase/Rac1 (ILK/Rac1) signaling pathway, survival and tumorigenic activity, angiogenesis-related to Vascular Endothelial Growth Factor (VEGF) activity, and metastasis [5-10]. Thymosin beta-4 (Tß4) has become a potent inducer of pancreatic cancer by triggering the increase of pro-inflammatory cytokine production through c-Jun NTerminal Kinase (JNK) signaling pathway activation and trigger EpithelialMesenchymal Transition (EMT) mechanism by upregulating ILK expression $[7,11]$.

Furthermore, it is suggested that thymosin beta- 4 (Tß4) regulate the increase of cell proliferation rate through enhancing $\beta$-catenin as an activator of $\mathrm{c}-\mathrm{Myc}$, and downregulate E-cadherin that results in loss of cell-cell adhesion [12]. Recently, AcSDKP is also associated with human malignant tumor as a potent stimulator of angiogenesis during tumor development, and under regulations of prolyl oligopeptidase (POP), this N-terminus sequence of $\mathrm{T} \beta 4$ induce cell survival through Phosphatidylinositol-3-Kinase/Akt (PI3KCA/Akt) pathway $[13,14]$. Even though some previous studies have investigated the profiles of amino acids in some cancers and the role of thymosin beta- 4 with the cleavage of this polypeptide AcSDKP, an advanced investigation on the fundamental function of AcSDKP activity in particular for pancreatic cancer subjects is still required.

This study aimed to investigate circulating AcSDKP in pancreatic cancer patients and to determine whether this small cleavage polypeptide can become a potential predictor for pancreatic cancer development. Moreover, this case-control study also aimed to evaluate the possible interaction between AcSDKP and other serologic parameters for PDAC. Therefore, we investigated the level of AcSDKP among healthy and pancreatic cancer patients to determine whether this polypeptide involved directly in PDAC pathogenesis.

\section{Methods}

\section{Study population}

This study employed an ongoing hospital-based case-control study conducted by affiliation between molecular, metabolic medicine laboratory, Department of Biological Science and Technology, National Chiao Tung University Hsinchu-Taiwan, and National Taiwan University Hospital Hsin-Chu Branch, Hsinchu, Taiwan. One hundred and five Taiwanese subjects were recruited to involve during this case- 
control study. In brief, 15 patients (healthy) and 90 patients (pancreatic cancer) were enrolled for clinical data collection. In addition, patients with severe conditions who could not fulfill the essential criteria of the samples were excluded during data collection. This study was approved by the institutional review board of the National Chiao Tung University Hsinchu, Taiwan, and written informed consent were obtained from all participants.

\section{Serological Test}

Blood and urine samples were acquired after overnight fasting and kept in an icebox immediately after collection. The serum was separated from erythrocytes by centrifuging at $1,500 \mathrm{~g}$ for $10 \mathrm{~min}$ at $4^{\circ} \mathrm{C}$. Furthermore, the serum and urine samples were frozen at minus $80^{\circ} \mathrm{C}$ and prepared for serologic and urine measurement of some parameters. The serum level of some variables was analyzed at the Department of Medical and Chemical Laboratory Diagnostics at the National Taiwan University Hospital Hsin-Chu Branch used routine procedures. The level of AcSDKP was quantified using a commercially available EnzymeLinked Immunosorbent Assay (ELISA) kit (SPI BIO, Bertin Group, France; catalog number A05881). In addition, the level of carbohydrate antigen 19-9 (CA 19-9) was measured by using the human ELISA kit (IBL America, catalog no. IB19124, Minneapolis, USA).

\section{Cell proliferation assay}

3-(4,5-dimethylthiazol-2-yl)-5-(3-carboxymethoxyphenyl)-2-(4-sulfophenyl)-2H-tetrazolium (MTS) assay for PDAC cell counting was used to assess cell proliferation rate. A $100 \mu \mathrm{L}$ aliquot of cells including AsPC, HPAC, and PANC- $1\left(3 \times 10^{3}\right.$ cells $/ \mathrm{mL}$ in $0.5 \%$ FBS and $1 \% \mathrm{P}+\mathrm{S}$ containing media) was added to a 96 well plate and incubated for 24 hours at $37^{\circ} \mathrm{C}$ in a humidified incubator containing $5 \% \mathrm{CO}_{2}$ in the air. For the control group, the cell was treated with $\mathrm{ddH} 2 \mathrm{O}$ and $0.1 \%$ DMSO, while for the experimental group all of that pancreatic cancer cell line ere induced with $100 \mu \mathrm{g} / \mathrm{mL}$ POP inhibitor, $100 \mu \mathrm{g} / \mathrm{mL}$ POP inhibitor $+10^{-7} \mathrm{M}$ AcSDKP, and $100 \mu \mathrm{g} / \mathrm{mL}$ POP inhibitor $+10^{-9} \mathrm{M}$ AcSDKP. After incubation for 24 hours, a ten $\mu \mathrm{L}$ MTS solution (MTS Cell Proliferation Colorimetric Assay Kit, Cat.\#K300-500, BioVision) was added to each well, and the incubation continued for 4 hours. The visible absorbance of each well was quantified at $490 \mathrm{~nm}$ using a microplate photometer.

\section{Statistical analysis}

All statistical analyses were performed using SPSS version 20.0 (IBM). The data were presented as mean \pm SEM for continuous variables. Moreover, to check the normality of data distribution, the KolmogorovSmirnov test was used, followed by parametric statistical analysis to compare differences and associations among all experimental groups. Overall, to compare differences between groups, unpaired ttest analyses were used. In addition, to assess the relationships between AcSDKP and other predictors, the correlation between all parameters were determined by Pearson's correlation (normally distributed data). Binary logistic regression was used to test the influence of clinical data and the levels of AcSDKP on the pancreatic status of patients. A $P$ value less than 0.05 was considered statistically significant. 


\section{Results}

\section{Subject characteristics}

The baseline characteristic of healthy and pancreatic cancer subjects are shown in Table 1. Indeed, fasting plasma blood glucose, triglyceride, alkaline phosphatase (ALP), alanine aminotransferase (ALT), aspartate aminotransferase (AST), amylase, and lipase were markedly increased in pancreatic cancer subjects compared to healthy patients. In particular, the levels of AcSDKP significantly increased, starting from $(0.73 \pm 0.13)$ in healthy subjects to $(1.34 \pm 0.14)$ for pancreatic cancer patients (Figure 1A). A similar pattern of serum cancer antigen 19-9 (CA 19-9) levels was observed in PDAC subjects compared to healthy control (Figure 1B). However, the level of hemoglobin and cholesterol was decreased steadily in pancreatic cancer subjects.

\section{AcSDKP induced proliferation rate in pancreatic cancer}

Further analysis was addressed to clarify the primary involvement of AcSDKP and its inhibitor during tumor growth. Here in our in vitro study, we found that pretreatment of AsPC, HPAC, and PANC-1 cell line using S17092, a specific prolyl oligopeptidase inhibitor (POPi) for AcSDKP synthesis, significantly decreased cell proliferation in all this pancreatic cancer cell line (Figure 2.A-C). Also, we found that cotreatment with AcSDKP peptide inversely increased cell number through stimulating proliferation rate.

\section{Univariate correlations of AcSDKP with the serologic marker in pancreatic cancer}

In this study, the fundamental association of AcSDKP and other serologic parameters are presented in Table 2. Overall, the level of AcSDKP had a positive correlation with pancreatic cancer status $(r=0.278, p$ $=0.026)$, betatrophin $(r=0.270, p=0.025), \operatorname{ALP}(r=0.267, p=0.034)$, ALT $(r=0.336, p=0.007)$, and AST $(r=0.255, p=0.042)$, while negatively correlated with cholesterol. On the other hand, there was no significant association between AcSDKP and CA 19-9 serum levels in PDAC subjects. Moreover, there was also no significant correlation with other serologic parameters in healthy and pancreatic cancer groups.

\section{Univariate binary logistic regression and quintile analysis in the total samples}

To determine whether the levels of AcSDKP are associated with the pancreatic cancer development and able to become independent predictor, we further analyzed the levels of AcSDKP and some serologic markers to predict pancreatic cancer progression in all samples.

AcSDKP was able to become an independent predictor for pancreatic cancer development. Univariate and multivariate binary logistic regression (Table $\mathbf{3} \mathbf{a}$ and $\mathbf{3 b}$ ) showed that the level of AcSDKP has a significant association with pancreatic cancer $[(p=0.031,0 R \pm 95 \% \mathrm{Cl}=3.342(1.117-10.002)]$ and $[(p=$ $0.024, \mathrm{OR} \pm 95 \% \mathrm{Cl}=4.324(1.030-18.148)]$. Moreover, AcSDKP also showed a significant correlation with fasting blood glucose $(F B G)[(p=0.001,0 R \pm 95 \% C l=1.034(1.014-1.053)]$, amylase $[(p=0.004$, $\mathrm{OR} \pm 95 \% \mathrm{Cl}=1.115(1.035-1.200)]$, lipase $[(p=0.002, \mathrm{OR} \pm 95 \% \mathrm{Cl}=1.108(1.039-1.181)]$, triglyceride $[(p$ $=<0.001, \mathrm{OR} \pm 95 \% \mathrm{Cl}=1.043(1.021-1.064)], \mathrm{ALP}[(p=0.003, \mathrm{OR} \pm 95 \% \mathrm{Cl}=1.066(1.023-1.111)], \mathrm{ALT}$ 
$[(p=0.008, O R \pm 95 \% C l=1.061(1.016-1.109)]$, and AST $[(p=0.014,0 R \pm 95 \% C l=1.131(1.025-1.247)]$. In addition, quintile analysis data (Table 4) showed that the level of AcSDKP strongly associated with serum betatrophin $[p=0.033,0 R \pm 95 \% C l=5.263(1.142-24.266)]$.

\section{Discussion}

AcSDKP linked lipid profile and metabolic disturbances to induce PDAC

Metabolic reprogramming is one of the essential hallmarks of cancer through increase oncogenic signaling pathways and directly enhances nutrient acquisition to promote lipids, proteins, and nucleic acid assimilation [15]. The net result of this process affects cancer cell growth and proliferation. Pancreatic ductal adenocarcinoma (PDAC) is a kind of tumor with hypovascularization to induce oxygen and nutrient delivery to the tumor. This tumor enhances PDAC aggressiveness during metabolic reprogramming. We hypothesized that AcSDKP might enhance pancreatic cancer associated with a metabolic imbalance in particular related to lipid and glucose metabolism. Moreover, it is suggested that AcSDKP activity accelerates pancreatic cancer progression through involving in metabolic reprogramming and enhancing neoangiogenesis within the tumor site.

Here in our study, we found that the level of fasting blood glucose tended to increase in pancreatic cancer patients. Furthermore, we also found that the level of triglyceride significantly increased in our samples. In line with the previous finding, in cancer development, oncogenic ras stimulates both glucose uptake via glucose transporter-1 (GLUT-1) and utilization of glucose by anabolic pathways. Linear to by Daemen et al. study, in this PDAC clinical samples, the lipogenic subtype is more sensitive to the epithelial cell. In contrast, the glycolytic subtype is associated with mesenchymal cells to induce PDAC progression [16]. The significant feature of lipid and glucose profile of our subjects may stimulate the acceleration of tumor growth, facilitate cancer cell proliferation, metastasis, and aggressiveness [17]. In brief, it clarifies that the increase in obesity incidence is associated with the early stage of pancreatic cancer development. We speculate that increased AcSDKP expression induces liver lipid metabolic hormone activity and corroborate pancreatic injury. However, further investigation is required to improve our hypothesis of whether AcSDKP related fatty pancreatic and pancreatic fibrosis incidence caused by hypertriglyceridemia.

AcSDKP may accelerate PDAC through enhancing neovascularization, cancer cell proliferation, and pancreatic fibrosis

PDAC is a common cause of death from cancer in the world that ranks first in the mortality rate of all cancer [7, 18], characterized by hypovascular and highly desmoplastic cancer [19], and the incidence is increasing in age groups of > 50 years. Due to the late symptoms, resection is associated with improved survival rate, but this is only possible in approximately $10 \%$ of patients [20]. According to the cancer therapy perspective, the identification of an angiogenic network is crucial to develop an antiangiogenic therapy [21]. Even though some biomarkers or prognostic factors of PDAC has been explored, further 
investigation to trace a sensitive and specific tumor predictor that may be more valuable in diagnosis, improving prognosis, and to improve clinical outcome in PDAC patients is still required.

This study attempted to explore the role of AcSDKP in pancreatic cancer development. Here in our study, we proposed an additional novel biomarker for pancreatic cancer, AcSDKP, a cleavage tetrapeptide of Thymosin $\beta 4$ as an inducer of cancer cell proliferation, migration, angiogenesis, and metastasis in many cancer cases. It has been established that growth and metastasis of pancreatic cancer depend on the activation of VEGF and other angiogenic factors. Signaling complex between cancer cells and adjacent endothelial cells is also suggested to promote aberrant vascularization/tumor angiogenesis [22]. Also, since pancreatic carcinoma shows active tumor neoangiogenesis, overexpression of a critical mediator of angiogenesis in pancreatic cancer (VEGF) becomes the target to develop anti-angiogenic therapies at present. Inhibition of neo-angiogenesis is a reliable and attractive target for tumor therapy. Indeed, the failure of the antiangiogenic agent is due to a single inhibitor that cannot inhibit the interconnection/network of angiogenesis signaling pathways [21]. Cross-inhibition of angiogenesis and apoptosis probably provide an extended benefit of combination cancer therapies consisting of antiangiogenics. Furthermore, establishing specific biomarker that plays a pivotal role in angiogenesis during PDAC development is essential to increase the patient survival rate.

Importantly, the study of Oh et al., 2010 has shown that TB4 paclitaxel treatment increases ROS production and triggers a significant increase in tumor density through hypoxia-inducible factor-1a (HIF1a) stabilization in HeLa human cervical tumor cells. This linear finding also similar to a fundamental characteristic of PDAC with hypovascularization and resistance to antiangiogenic inhibitor in specific pathways. Moreover, a study claims that tolfenamic acid is a potential nonsteroidal anti-inflammatory drug (NSAID) to reduce angiogenesis through VEGF signaling pathway by degrading transcription factor Sp1, Sp3, and Sp4; and decrease tumor growth and metastasis [23]. On the other hand, another study suggests that the lower efficacy of VEGF-antiangiogenic drugs is due to the main focus of these treatments related to angiogenesis inhibition without combination to reduce tumor malignancy [24].

Previous studies have shown that T $\beta 4$ is a potent inducer of angiogenesis in cancer development that presents in blood at nanomolar concentration, and relates to angiogenesis in particular for pancreatic cancer $[7,14]$. T $\beta 4$ also increases pancreatic cancer incidence (through inducing the elevation of proinflammatory cytokine production), increases the number of metastasis tumors, represses the anticancer immunity, controls tumor cell migration in angiogenesis, and controls tumor metastasis through HIF-1 a $[8,25,26]$. T $\beta 4$ is a small tetrapeptide that can be a novel target for the therapeutic approach of cancer, mainly tumor dormancy [25]. Besides, it also indicated accelerated severity and decreased the survival rate in multiple myeloma [10]. The solid tumor shows a switching process by changing the balance between angiogenesis inducer and countervailing inhibitor. Interestingly, the AcSDKP concentration is significantly increased within the intratumor blood of patients under the regulation of POP (prolyl oligopeptidase) [14, 27]. Indeed, AcSDKP has a unique function related to a particular pathologic condition. The amino-terminal site contains four amino acid that able to block inflammation and reduce fibrosis Transforming Growth Factor- $\beta$ (TGF $\beta$ ) signaling pathways [28-30], 
while another site of this polypeptide (amino terminus with 15 amino acids) promotes cell survival and inhibits apoptosis, angiogenesis, cell migration, and wound healing [30, 31].

Importantly, our study found that the level of AcSDKP significantly increased in pancreatic cancer patients, suggested that this pathological condition stimulates the increase of POP activity and angiogenesis to support tumor growth. However, the limitation of our study, we still cannot provide a complete molecular signaling network between AcSDKP and other biomarkers involved in pancreatic cancer. It is only hypothesized that the possible mechanism of AcSDKP activity during pancreatic cancer development by triggering the activation of pro-angiogenic molecules, cancer cell proliferation, and induced migration. Moreover, AcSDKP may be associated with other oncometabolomic molecules involved in nutrient supply, metabolic disturbances, and pancreatic fibrosis during cancer development. Therefore, further investigation should be addressed to the molecular pathways of AcSDKP in pancreatic cancer through EMT markers activity, and the downstream of pro-angiogenic inducer, in particular, VEGF as the potential targets for cancer therapy.

\section{AcSDKP associated with betatrophin in pancreatic cancer}

We also studied the correlation between AcSDKP to other parameters in pancreatic cancer progression. From our previous study, we found that the elevation of betatrophin concentration also correlates with pancreatic cancer incidence in patients with diabetes [32]. Here, our study showed that an attractive feature, whereas the level of AcSDKP is strongly associated with the serum level of betatrophin. This finding provides a novel molecular cross interaction between AcSDKP and betatrophin. Furthermore, the increase of AcSDKP concentration is in line with the elevation of liver injury markers (ALT, AST, and ALP). AcSDKP and betatrophin are produced in the liver, and both of these molecules suggested to regulate pancreatic cancer development that results in liver injury. Here in our study, the level of triglyceride and cholesterol also increases significantly in pancreatic cancer subjects. It is established that betatrophin regulates the degree of triglyceride by activating lipoprotein lipase $(L P L)$ as the primary enzyme of triglycerides synthesis from lipid metabolism [33,34]. In vivo study showed that knockout of betatrophin reveals about 70\% reduction in plasma levels of [35]. Furthermore, it remains unknown whether pancreatic cancer patients stimulate the increase of hepatic AcSDKP expression to induce the elevation of betatrophin. In addition, our study also demonstrated that the serum levels of betatrophin were significantly correlated with AcSDKP levels.

In further analysis of this study, we found an exciting feature, whereas the serum levels of betatrophin can predict the pancreatic cancer progression by increase the odds-ratio of AcSDKP by quintile analysis. We speculate that AcSDKP corroborates pancreatic cancer development through cross molecular connection with betatrophin-LPL activity induce the increase of triglyceride levels. As a result, this pathological initiation process causes fatty pancreas as the pre-cancerous lesions during PDAC development. However, the underlying pattern of the molecular mechanism of this phenomenon is still unknown, and whether AcSDKP-betatrophin molecular interaction in pancreatic cancer associated with pancreatic fibrosis is not entirely elucidated. 


\section{Conclusions}

In summary, circulating AcSDKP is significantly associated with pancreatic ductal adenocarcinoma development. AcSDKP was strongly correlated with serum levels of betatrophin and had a positive correlation to liver injury marker. Therefore, the levels of AcSDKP may serve as a potential additional prognostic biomarker for the early diagnosis of PDAC progression.

\section{Abbreviations}

T $\beta 4$ : Thymosin $\beta-4$

AcSDKP : N-Acetyl-Seryl-Aspartyl-Lysyl-Proline

PDAC : Pancreatic Ductal Adenocarcinoma

POP : Prolyl Oligopeptidase

ILK/Rac1 : Integrin-Linked Kinase/Rac1

VEGF : Vascular Endothelial Growth Factor

JNK : c-Jun N-Terminal Kinase

EMT : Epithelial Mesenchymal Transition

PI3K/Akt : Phophatidylinositol-3-Kinase/Akt

ALP : Alkaline Phosphatase

ALT : Alanine Aminotransferase

AST : Aspartate Aminotransferase

CA 19-9 : Cancer Antigen 19-9

FBG : Fasting Blood Gluocose

GLUT-1 : Glucose Transporter-1

HIF-1a : Hypoxia-Inducible Factor-1a

NSAID : Nonsteroidal Anti-Inflammatory Drugs

TGF- $\beta$ : Transforming Growth Factor- $\beta$

LPL : Lipoprotein Lipase 


\section{Declarations}

\section{Ethics approval and consent to participate}

This work has been approved by the Research Ethics Committee for Human Subject Protection National Chiao Tung University with the application number NCTU-REC-103-021. All participants have decided to participate in this study after reading all the considerations within the informed consent form and fill the form without prejudice.

\section{Consent for publication}

All the authors have been agreed that all the information (text and any pictures) within this manuscript may be seen by the general public. All authors declare that the paper is not under consideration for publication in another journal and will not be submitted elsewhere until the editorial refereeing process is completed.

\section{Availability of data and material}

The datasets generated during and/or analyzed during the current clinical study are available on reasonable request to the corresponding author.

\section{Competing interest}

The author declares that there is no conflict of interest in the field covered by this manuscript.

\section{Funding}

This study was supported by the Ministry of Science and Technology, Taiwan, Republic of China, with grants number 102-2320-B-009 -002 -MY3 and 104-2321-B-009-001. This work was also supported by the Ministry of Science and Technology I-RiCE Program with Grant Number 103-2911-I-009-101. The funders had no rule in the study design, data collection, and analysis, decision to publish, or preparation of the manuscript.

\section{Authors' contributions}

$\mathrm{CHW}$ conceived the research and contributed to the research project design, the data interpretation, and writing of the manuscript. HS contributed to the participant recruiting, laboratory work and data collection, analyzed the clinical data, and writing of the manuscript. JDTP and CCC contributed to the research project design, participant recruiting, and statistical analysis of the clinical data. All authors have read and approved the manuscript.

\section{Acknowledgements}

I would like to thank all the MD colleagues at National Taiwan University Hospital HsinchuBranch who have been involved in this study. Also, we appreciate the Ministry of Science and Technology, Taiwan- 
ROC, for the grant of this clinical investigation.

\section{References}

1. Yuan $C$, Rubinson DA, Qian ZR, Wu C, Kraft $P, B a o Y$, et al. Survival among patients with pancreatic cancer and long-standing or recent-onset diabetes mellitus. J Clin Oncol. 2015;33:29-35.

2. van der Zee JA, van Eijck CHJ, Hop WCJ, van Dekken H, Dicheva BM, Seynhaeve ALB, et al. Expression and prognostic significance of thymidylate synthase (TS) in pancreatic head and periampullary cancer. Eur J Surg Oncol. 2012;38:1058-64.

3. Blum R, Kloog Y. Metabolism addiction in pancreatic cancer. Cell Death Dis. 2014;5:e1065.

4. Patel R, Ede J, Collins J, Willens D. Pancreatic cancer presenting as new-onset diabetes. Case Rep Oncol. 2014;7:171-4.

5. Tang M-C, Chan L-C, Yeh Y-C, Chen C-Y, Chou T-Y, Wang W-S, et al. Thymosin beta 4 induces colon cancer cell migration and clinical metastasis via enhancing ILK/IQGAP1/Rac1 signal transduction pathway. Cancer Lett. 2011;308:162-71.

6. Ricci-Vitiani L, Mollinari C, di Martino S, Biffoni M, Pilozzi E, Pagliuca A, et al. Thymosin beta4 targeting impairs tumorigenic activity of colon cancer stem cells. FASEB J. 2010;24:4291-301.

7. Zhang Y, Feurino LW, Zhai Q, Wang H, Fisher WE, Chen C, et al. Thymosin Beta 4 is overexpressed in human pancreatic cancer cells and stimulates proinflammatory cytokine secretion and JNK activation. Cancer Biol Ther. 2008;7:419-23.

8. Cha $\mathrm{H}-\mathrm{J}$, Jeong M-J, Kleinman HK. Role of thymosin beta4 in tumor metastasis and angiogenesis. $\mathrm{J}$ Natl Cancer Inst. 2003;95:1674-80.

9. Bock-Marquette I, Saxena A, White MD, Michael DiMaio J, Srivastava D. Thymosin $\beta 4$ activates integrin-linked kinase and promotes cardiac cell migration, survival and cardiac repair. Nature. 2004;432:466-72.

10. Caers J, Hose D, Kuipers I, Bos TJ, Van Valckenborgh E, Menu E, et al. Thymosin $\beta 4$ has tumor suppressive effects and its decreased expression results in poor prognosis and decreased survival in multiple myeloma. Haematologica. 2010;95:163-7.

11. Ryu Y-K, Kang J-H, Moon E-Y. The actin-sequestering protein thymosin beta-4 is a novel target of hypoxia-inducible nitric oxide and HIF-1a regulation. PLoS ONE. 2014;9:e106532.

12. Wang W-S, Chen P-M, Hsiao H-L, Ju S-Y, Su Y. Overexpression of the thymosin beta-4 gene is associated with malignant progression of SW480 colon cancer cells. Oncogene. 2003;22:3297-306.

13. Hu P, Li B, Zhang W, Li Y, Li G, Jiang X, et al. AcSDKP regulates cell proliferation through the PI3KCA/Akt signaling pathway. PLoS ONE. 2013;8:e79321.

14. Liu J-M, Kusinski M, Ilic V, Bignon J, Hajem N, Komorowski J, et al. Overexpression of the angiogenic tetrapeptide AcSDKP in human malignant tumors. Anticancer Res. 2008;28:2813-7.

15. Boroughs LK, DeBerardinis RJ. Metabolic pathways promoting cancer cell survival and growth. Nat Cell Biol. 2015;17:351-9. 
16. Daemen A, Peterson D, Sahu N, McCord R, Du X, Liu B, et al. Metabolite profiling stratifies pancreatic ductal adenocarcinomas into subtypes with distinct sensitivities to metabolic inhibitors. Proc Natl Acad Sci USA. 2015;112:E4410-4417.

17. Rebours V, Gaujoux S, d’Assignies G, Sauvanet A, Ruszniewski P, Lévy P, et al. Obesity and Fatty Pancreatic Infiltration Are Risk Factors for Pancreatic Precancerous Lesions (PanIN). Clin Cancer Res. 2015;21:3522-8.

18. Cui Y, Brosnan JA, Blackford AL, Sur S, Hruban RH, Kinzler KW, et al. Genetically defined subsets of human pancreatic cancer show unique in vitro chemosensitivity. Clin Cancer Res. 2012;18:6519-30.

19. Mathew E, Zhang Y, Holtz AM, Kane KT, Song JY, Allen BL, et al. Dosage-dependent regulation of pancreatic cancer growth and angiogenesis by hedgehog signaling. Cell Rep. 2014;9:484-94.

20. Sikkens ECM, Cahen DL, de Wit J, Looman CWN, van Eijck C, Bruno MJ. Prospective assessment of the influence of pancreatic cancer resection on exocrine pancreatic function. Br J Surg. 2014;101:109-13.

21. Abdollahi A, Schwager C, Kleeff J, Esposito I, Domhan S, Peschke P, et al. Transcriptional network governing the angiogenic switch in human pancreatic cancer. Proc Natl Acad Sci USA. 2007;104:12890-5.

22. Maity G, Mehta S, Haque I, Dhar K, Sarkar S, Banerjee SK, et al. Pancreatic tumor cell secreted CCN1/Cyr61 promotes endothelial cell migration and aberrant neovascularization. Sci Rep. 2014;4:4995.

23. Abdelrahim M, Baker $\mathrm{CH}$, Abbruzzese JL, Safe S. Tolfenamic acid and pancreatic cancer growth, angiogenesis, and Sp protein degradation. J Natl Cancer Inst. 2006;98:855-68.

24. Welti J, Loges S, Dimmeler S, Carmeliet P. Recent molecular discoveries in angiogenesis and antiangiogenic therapies in cancer. J Clin Invest. 2013;123:3190-200.

25. Goldstein AL. Thymosin $\beta 4$ : A New Molecular Target for Antitumor Strategies. J Natl Cancer Inst. 2003;95:1646-7.

26. Oh J-M, Moon E-Y. Actin-sequestering protein, thymosin beta-4, induces paclitaxel resistance through ROS/HIF-1alpha stabilization in HeLa human cervical tumor cells. Life Sci. 2010;87:286-93.

27. Myöhänen TT, Tenorio-Laranga J, Jokinen B, Vázquez-Sánchez R, Moreno-Baylach MJ, GarcíaHorsman JA, et al. Prolyl oligopeptidase induces angiogenesis both in vitro and in vivo in a novel regulatory manner. Br J Pharmacol. 2011;163:1666-78.

28. Chen Y-W, Liu B-W, Zhang Y-J, Chen Y-W, Dong G-F, Ding X-D, et al. Preservation of basal AcSDKP attenuates carbon tetrachloride-induced fibrosis in the rat liver. J Hepatol. 2010;53:528-36.

29. Kanasaki K, Koya D, Sugimoto T, Isono M, Kashiwagi A, Haneda M. N-Acetyl-serylaspartyl-lysylproline inhibits TGF-beta-mediated plasminogen activator inhibitor-1 expression via inhibition of Smad pathway in human mesangial cells. J Am Soc Nephrol. 2003;14:863-72.

30. Sosne G, Qiu P, Goldstein AL, Wheater M. Biological activities of thymosin beta4 defined by active sites in short peptide sequences. FASEB J. 2010;24:2144-51. 
31. Smart N, Dubé KN, Riley PR. Identification of Thymosin $\beta 4$ as an effector of Hand1mediated vascular development. Nat Commun. 2010;1:46.

32. Susanto H, Liu T-Y, Chen C-C, Purnomo JDT, Chen S-F, Wang C-H. Increased serum levels of betatrophin in pancreatic cancer-associated diabetes. Oncotarget. 2016;7. doi:10.18632/oncotarget.9815.

33. Zhang R, Abou-Samra AB. Emerging roles of Lipasin as a critical lipid regulator. Biochem Biophys Res Commun. 2013;432:401-5.

34. Fenzl A, Itariu BK, Kosi L, Fritzer-Szekeres M, Kautzky-Willer A, Stulnig TM, et al. Circulating betatrophin correlates with atherogenic lipid profiles but not with glucose and insulin levels in insulinresistant individuals. Diabetologia. 2014;57:1204-1208.

35. Wang Y, Quagliarini F, Gusarova V, Gromada J, Valenzuela DM, Cohen JC, et al. Mice lacking ANGPTL8 (Betatrophin) manifest disrupted triglyceride metabolism without impaired glucose homeostasis. Proceedings of the National Academy of Sciences. 2013;110:16109-16114.

\section{Tables}

Table 1: Baseline Characteristics of the Patients and Control Subjects

\begin{tabular}{lccc}
\hline & Healthy & Pancreatic Cancer & $P$-value \\
\hline $\mathrm{n}$ & 15 & 90 & - \\
FBG (mg/dL) & $101.80 \pm 4.78$ & $179.92 \pm 7.01$ & $<0.0001^{*}$ \\
\hline Hemoglobin (\%) & $14.45 \pm 0.48$ & $12.13 \pm 0.15$ & $<0.0001^{*}$ \\
\hline Cholesterol (mg/dL) & $180.33 \pm 11.50$ & $106.32 \pm 2.86$ & $<0.0001^{*}$ \\
\hline Triglyceride (mg/dlL) & $100.93 \pm 16.94$ & $180.85 \pm 6.50$ & $0.0009^{*}$ \\
\hline Amylase (U/L) & $28.67 \pm 2.15$ & $253.89 \pm 46.17$ & $0.0294^{*}$ \\
\hline Lipase (U/L) & $20.73 \pm 1.80$ & $554.93 \pm 85.37$ & $0.0065^{*}$ \\
\hline ALP (IU/L) & $41.53 \pm 3.86$ & $303.07 \pm 21.31$ & $<0.0001^{*}$ \\
\hline ALT (IU/L) & $22.80 \pm 1.80$ & $180.93 \pm 20.67$ & $0.0024^{*}$ \\
\hline AST (IU/L) & $20.90 \pm 1.44$ & $135.32 \pm 14.21$ & $0.0013^{*}$ \\
\hline
\end{tabular}

Abbreviation: FBG, Fasting Blood Glucose; ALP. Alkaline Phosphatase; ALT, Alanine Aminotransferase; AST, Aspartate Aminotransferase.

Data are means \pm SEM with $P$-value $<+0.05$ significantly different between any groups. ${ }^{\wedge}$ pancreatic cancer vs. Healthy subjects $(\mathrm{H})$

Table 2: Correlations between AcSDKP and Other Variables in All Study Participants, Healthy Group, and Pancreatic Cancer Group by Person Product-Moment 


\begin{tabular}{|c|c|c|c|c|c|c|}
\hline & $r$ & $P$-value & $r$ & $P$-value & $r$ & $P$-value \\
\hline Betatrophin & 0.270 & $0.025 *$ & - & - & - & - \\
\hline CA 19-9 & -0.122 & 0.413 & - & - & - & - \\
\hline FBG & -0.004 & 0.975 & 0.432 & 0.108 & -0.195 & 0.180 \\
\hline Hemoglobin & -0.064 & 0.613 & -0.488 & 0.065 & 0.011 & 0.946 \\
\hline Cholesterol & -0.250 & $0.046^{*}$ & -0.062 & 0.827 & -0.090 & 0.540 \\
\hline Triglyceride & 0.065 & 0.609 & -0.249 & 0.370 & -0.059 & 0.685 \\
\hline Amylase & 0.089 & 0.526 & -0.170 & 0.544 & 0.011 & 0.946 \\
\hline Lipase & 0.251 & 0.064 & -0.247 & 0.374 & 0.177 & 0.275 \\
\hline ALP & 0.267 & $0.034 *$ & 0.027 & 0.925 & 0.137 & 0.353 \\
\hline $\mathrm{ALT}$ & 0.336 & $0.007^{*}$ & 0.121 & 0.668 & 0.274 & 0.057 \\
\hline AST & 0.255 & $0.042 *$ & 0.461 & 0.083 & 0.170 & 0.242 \\
\hline
\end{tabular}

* significant correlation with $p<0.05$.

Table 3a: Univariate Binary Logistic Regression Analysis with Pancreatic Cancer 


\begin{tabular}{lccc} 
Covariates & OR & P-value & 95\% CI for OR \\
\hline AcSDKP & 3.342 & $0.031^{*}$ & $(1.117-10.002)$ \\
CA 19-9 & 1.059 & 0.097 & $(0.990-1.132)$ \\
\hline FBG & 1.034 & $0.001^{*}$ & $(1.014-1.053)$ \\
\hline Amylase & 1.115 & $0.004^{*}$ & $(1.035-1.200)$ \\
\hline Lipase & 1.108 & $0.002^{*}$ & $(1.039-1.181)$ \\
\hline Cholesterol & 0.95 & $<0.001^{*}$ & $(0.929-0.972)$ \\
\hline Triglyceride & 1.043 & $<0.001^{*}$ & $(1.021-1.064)$ \\
\hline Hemoglobin & 0.359 & $<0.001^{*}$ & $(0.218-0.593)$ \\
\hline ALP & 1.066 & $0.003^{*}$ & $(1.023-1.111)$ \\
\hline ALT & 1.061 & $0.008^{*}$ & $(1.016-1.109)$ \\
\hline AST & 1.131 & $0.014^{*}$ & $(1.025-1.247)$ \\
\hline
\end{tabular}

Odds-ratio (OR) and $\mathrm{p}$ values are given. ${ }^{*}$ significant with $p<0.05$.

Table 3b: Multivariate Binary Logistic Regression Analysis with Pancreatic Cancer Covariates OR P-value P-value adjusted (FDR) 95\% CI for OR

\begin{tabular}{llllc}
\hline AcSDKP & 4.324 & 0.045 & $0.024^{*}$ & $(1.030-18.148)$ \\
Triglyceride & 1.036 & 0.001 & $0.000^{*}$ & $(1.015-1.057)$
\end{tabular}

Odds-ratio (OR), $\mathrm{p}$ values, and $\mathrm{p}$ value adjusted (false discovery rate $=$ FDR) are given.

* significant with $p<0.05$.

Table 4. Relationship [OR (95\%)CI] between AcSDKP and Other Parameters in Pancreatic Cancer 


\begin{tabular}{|c|c|c|c|c|c|c|}
\hline \multirow{2}{*}{ Variable } & \multicolumn{2}{|c|}{ Quintile 1} & Quintile 2 & \multicolumn{3}{|c|}{ Quintile 3} \\
\hline & $\begin{array}{l}\text { OR } \\
(95 \% \mathrm{CI})\end{array}$ & $P$ & OR $(95 \% \mathrm{CI}) \quad P$ & OR $(95 \% \mathrm{CI})$ & & $P$ \\
\hline FBG & 1.000 & - & $\begin{array}{l}1.008(0.999-0.096 \\
1.018)\end{array}$ & $\begin{array}{c}1.007(0.997- \\
1.016)\end{array}$ & & 0.181 \\
\hline Betatrophin & 1.000 & - & $\begin{array}{l}0.660(0.154-0575 \\
\quad 2.827)\end{array}$ & 5.263 & 24.266) & $0.033^{*}$ \\
\hline Amylase & 1.000 & - & $\begin{array}{l}0.997(0.992-0.263 \\
\quad 1.002)\end{array}$ & $\begin{array}{l}1.001(0.999- \\
1.003)\end{array}$ & & 0.361 \\
\hline Lipase & 1.000 & - & $\begin{array}{l}0.999(0.997-0.143 \\
\quad 1.000)\end{array}$ & $\begin{array}{l}1.001(1.000- \\
1.002)\end{array}$ & & 0.174 \\
\hline Cholesterol & 1.000 & - & $\begin{array}{l}0.996(0.983-0.520 \\
\quad 1.009)\end{array}$ & $\begin{array}{l}0.986(0.970- \\
1.001)\end{array}$ & & 0.068 \\
\hline Triglyceride & 1.000 & - & $\begin{array}{l}1.002(0.991-0.738 \\
\quad 1.012)\end{array}$ & $\begin{array}{c}1.004(0.994- \\
1.014)\end{array}$ & & 0.459 \\
\hline Hemoglobin & 1.000 & - & $\begin{array}{l}0.844(0.584-0.366 \\
\quad 1.219)\end{array}$ & $\begin{array}{l}0.932(0.653- \\
1.329)\end{array}$ & & 0.696 \\
\hline ALP & 1.000 & - & $\begin{array}{l}1.001(0.998-0.474 \\
\quad 1.005)\end{array}$ & $\begin{array}{l}1.003(0.999- \\
1.006)\end{array}$ & & 0.101 \\
\hline ALT & 1.000 & - & $\begin{array}{l}1.002(0.998-0.326 \\
\quad 1.007)\end{array}$ & $\begin{array}{l}1.004(1.000- \\
1.009)\end{array}$ & & 0.066 \\
\hline AST & 1.000 & - & $\begin{array}{l}1.004(0997-0.281 \\
1.010)\end{array}$ & $\begin{array}{c}1.005(0.999- \\
1.012)\end{array}$ & & 0.088 \\
\hline
\end{tabular}

Q1 is the reference. ${ }^{*}$ significant with $p<0.05$.

\section{Figures}

A

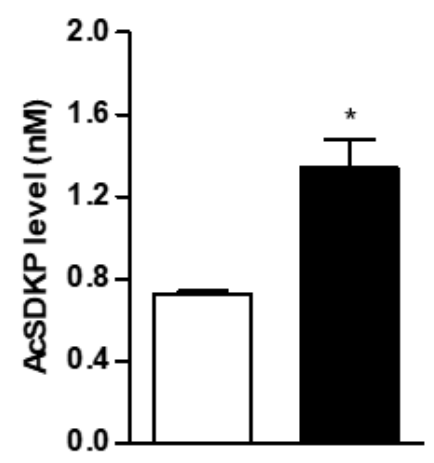

B

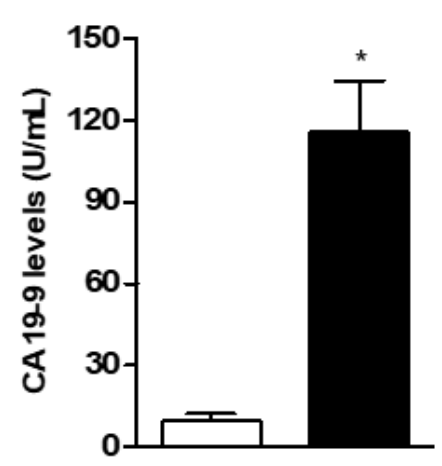


Figure 1

The level of AcSDKP and CA 19-9 in pancreatic cancer Data are means \pm SEM with a P-value $<0.05$ significantly different between any groups.

A

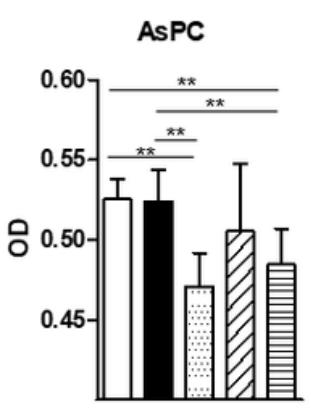

B

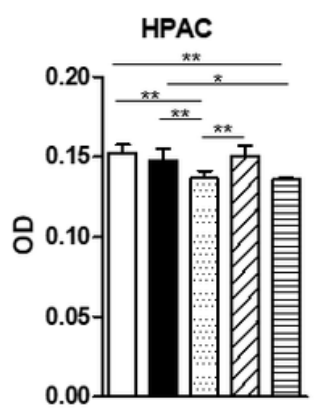

C

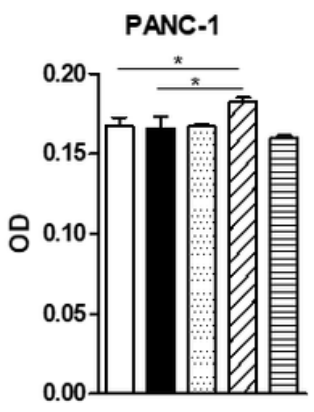

$\square$ Control

$0.1 \%$ DMSO

POPi $100 \mu \mathrm{g} / \mathrm{mL}$

$\square$ POPi $100 \mu \mathrm{g} / \mathrm{mL}+10^{-9} \mathrm{M}$ AcSDKP

目 POPi $100 \mathrm{mg} / \mathrm{mL}+10^{-7} \mathrm{MACSDKP}$

Data are means \pm SEM. * a $p$ value $<0.05$; ${ }^{\star \star}$ a $p$ value $<0.01$

\section{Figure 2}

AcSDKP induced pancreatic cancer cell proliferation Data are means \pm SD with a P-value $<0.05$ significantly different between any groups. 